\title{
Research on the Soft Environment of Industrial Park in China: Function, Connotation and Optimizing Countermeasure
}

\author{
Jie ZHEN \\ Business School, East China University of Political Science and Law, P.R. China, 201620 \\ jetzhen@163.com \\ ${ }^{*}$ Corresponding author
}

Keywords: Soft environment, Industrial park, Function, Connotation.

\begin{abstract}
Based on the analysis of the importance of the soft environment, this paper divides the soft environment of the industrial park into four types which are industrial matching, life services, park wisdom and park culture according to its function and effect. Then the paper elaborates the connotation and features of each type of the soft environment. Finally, with the understanding of the problems of the soft environment, the paper provides some optimization strategies.
\end{abstract}

\section{Introduction}

Industrial parks are the important platform for China's economic development, and the parks contribute $12.8 \%$ of the country's GDP with only less than $2 \%$ of the national territory area. The number of China's national industrial parks have reached to 527 up to the end of 2016. Among of them, the top 100 national parks contribute $78 \%$ of all the national economic and technological development zones and high-tech industrial development zones [1]. The development of China's industrial parks is marked by Dalian economic and technological development zone in 1984 and has lived through four stages including initial cultivation, rapid growth, steady development, innovation and upgrading which are driven by preferential policies on land, taxation and talents. However, the dividend of polices of the parks' development has been weakened at present. Especially, the parks had encountered the obvious pressure and challenges coming from economic downturn in 2016 and now cry for cultivating new impetuses to carry out transformation and upgrading and sustainable development as well.

\section{The Vital Function of Constructing the Soft Environment of Industrial Park}

China State Council has approved 17 independent innovation demonstration zones involving Beijing zhongguancun zone and Shanghai zhangjiang zone up to 2016. In 2016, China launched the construction of the first batch of ecological civilization pilot zone and selected Fujian, Jiangxi and Guizhou to carry out the pilot. Therefore, the construction of high quality soft environment will contribute to the new strategic mission of the parks.

According to the basic function of the park, the construction of soft environment can contribute to strengthen the agglomeration capacity inside the park. First of all, the complete industrial supporting facilities in the park can bring together the agglomeration economic effects of the sharing of infrastructure and factor resources, the reduction of comprehensive transaction costs, and the formation of technological overflow innovation environment. Secondly, the intellectualization of the park can revitalize the carriers and resources embracing various services in the industrial parks, and integrate all kinds of resources which are cross-industry, cross-major, cross-department and related to the industries of the park, which is beneficial to improve the agglomeration function of the park. Finally, creating a cultural environment that supports innovation, takes risks and tolerates failure can strengthen unity and cooperation among innovation subjects and enhance cohesion within the park.

Judging from the outside attraction of the park, the construction of soft environment can help the park to improve the competitive advantage. On the one hand, the life service belongs to 
supportability elements constituting the zone and is closely related to "happiness" of the enterprises in the park, which determines the attraction of the park to a large extent and forms the differentiation among the various parks. On the other hand, three types of culture have been shaped in the process of constructing the park culture, which involve innovative culture featuring with forging ahead and collaborative sharing, humanistic culture featuring with gathering elite from anywhere and all-round development, green culture featuring with improving energy structure and efficiency. It is conducive to expand investment attraction, draw in excellent enterprises and talents, and promote the sustainable development of the park. In addition, the specialized estate developers being good at operating the parks such as China Fortune Land Development Co., Ltd, LIANDO U valley get involved in the transformation and upgrading of the park and promote the external competitive advantage of the park through the construction of soft environment.

\section{The Connotation and Type of the Soft Environment of the Industrial Park}

The soft environment of industrial parks refers to the sum of factors and conditions providing indemnificatory and ameliorative services for the production and living in certain areas of the parks. According to its function and effect, the soft environment of industrial parks is composed of four aspects: industrial matching, life services, park wisdom and park culture (See Figure1), thereby the innovation and transformation and upgrading of the park being realized.

Industrial parks have always attached great importance to their production function, and constantly build and perfect the longitudinal supply chain and horizontal productive service chain while neglect their living function, namely, providing the high quality of education, health care and a variety of park cultures. After more than 30 years of development, the soft environment of industrial parks can overall play a indemnificatory role, providing basic industrial matching and living service for the parks. However, there is still a lot of growth potential in providing a good culture for the park and improving the development of smart parks.

Production Function Living Function

\begin{tabular}{|l|c|c|}
\cline { 2 - 3 } Indemnificatory Effect & Industrial Matching & Life Services \\
& & \\
\cline { 2 - 3 } Ameliorative Effect & Park Wisdom & Park Culture \\
& & \\
\hline
\end{tabular}

Fig. 1 Elements of the soft environment of the industrial park

Industrial matching provides the leading industry and enterprises in the park indemnificatory content involving the industrial chain, investment and financing, human resources, logistics, research and development. The formation of the industrial matching system is the critical driving force for the development of the industries in the park, and its perfection is measured by the degree of asset specificity [2] and the integrity of the industrial chain [3].

Park wisdom provides the improvement content of scientific decision-making and efficient innovation for the park management institutions and enterprises, including the information infrastructure and the application of informatization. Combined with "Internet plus", the park wisdom integrates with the new generation of information technology such as Internet of things, cloud computing and big data. The development of park wisdom can be divided into three phrases which are information-based, knowledge-driven and intelligence-led. The performance should be evaluated by four first grade assessment indicators including programme, construction, operation and maintenance, and service of the park wisdom [4]. 
Life service provides the indemnificatory public service for the staff in the park, including the basic service which involves food, shelter, travel, medical treatment and the uplifting service which includes education, entertainment, leisure, ecological construction and so on. The life service in the park is closely related to the "happiness" of the staff, which largely determines the attraction of the park to the enterprises and their employees and helps to enhance the soft power of the park.

The park culture provides the humanistic environment and working atmosphere which is consistent with the sustainable development of the park, including innovation culture, green culture and humanistic culture. The operation principles, values and behavior reflected by park culture is conducive to effectively integrate various resources, encourage open innovation and transformation and upgrading of the industrial parks, reduce the management costs of the parks and thus form unique competitive advantages.

\section{The Problems of Soft Environment of Industrial Park and Optimization Strategy}

At present, the level of soft environment construction in China's industrial parks is generally not high, and there are certain problems in the four aspects of industrial matching, park wisdom, life service and park culture.

In terms of industrial matching, all the links of the industrial chain don't have closed correlation with each other, investment and financing service system is not perfect enough, the level of human resource management service is not high, and the construction speed of research and development supporting is relatively slow. This is due to the fact that the leading industries in the park are miscellaneous and their relevance is not strong, meanwhile the supporting system is difficult to be improved. On the other hand, the relevant matching problems in the park are not paid enough attention. Therefore, the parks should firstly bring the park matching bring into their development plans, construct the park matching system, enhance the competitiveness of the industry chain in the parks through adding the parks' value by integrating, extending and expanding the industry chain. Then the parks should set up the institutional framework which can promote industrial matching such as coordination office, and gradually perfect the intermediary agencies and related service system in order to provide service for supporting the development of the enterprises in the parks. Finally, the parks should carry out longitudinal and horizontal matching. The longitudinal matching refers to the transfer and undertaking among the upstream and downstream industries centering on the advantages of industry and resources. The horizontal matching involves various services in the field of information, bank, insurance, human resources, logistics, research and development.

As for park wisdom, there is no synergy effect in the park because of the dispersed state of infrastructure construction, park management and services. The fusion of informatization and industrialization still has vacancy and the development level of smart park is unbalanced. For the time being, the intelligent construction of China's industrial parks has formed the spatial pattern featuring as coastal gathering in eastern China, interconnecting along Yangtze river in central China, and characteristic development in western China. In China, 44 state-level development zones and 45 state-level high-tech zones are advancing the construction of park wisdom, respectively account for $20 \%$ and $31 \%$. The constructing emphases focus on information infrastructure and e-government. Moreover, the industrial parks in the eastern region are taking the leading position due to the advantages in geography superiority, urban economic development and policy support. Thus, the industrial parks, at the beginning of the park wisdom, need to cultivate the internet thinking complying with the gradual development of the three levels including information-based, knowledge-driven and intelligence-led. The parks should carry out the upgrading and rebuilding to the traditional industries and enterprises through "internet + " and promote their transformation by the combination of online and offline.

In the field of life services, the industrial parks are facing some noteworthy problems, for example, the cultural education level is limited, the medical facilities are imperfect, the entertainment service system is poor, the living function becomes short board in the evolution of the parks, and the policies and incentives for the development of the ecological parks are still preliminary. The main reason of forming the situation is that the driving force of the park 
development has always been the preferential policy and the infrastructure while is lack of strictly implement of city and industry integration. At present, 108 parks have been approved to carry out the construction of national eco-industrial demonstration parks and 45 parks have been approved to be national ecological parks. In order to further play the role of life service function, the industrial parks should actively invest their resources to perfect the cultural education system, raise the medical level in many ways, introduce a leisure entertainment system with its own characteristics, create a good living environment, strengthen the construction of the ecological parks.

In the aspect of park culture, the position of cultural construction is incorrect, the innovative impetus is insufficient, the humanistic culture is deficiency, and the green culture needs to be strengthened. Compared with enterprise culture, the park culture should be more inclusive, integrative and leading. However, many industrial parks haven't put forward specific cultural content conforming to the strategic thought and distinctive image of the parks since they haven't combined their actual situation and strategic position. Thus, the industrial parks are lack of consideration and support for innovation culture, humanistic culture and green culture at the spiritual level, institutional level and material level. Because of this, the parks need to be operated according to the reality and fully mine the characteristics of the parks in cultivating the culture. To be specific, the parks should construct the distinctive culture from the overall level of the park, the enterprise level in the park and the staff level in the park, in order to effectively gather innovative resources and create an atmosphere of innovation, strengthen humanistic care and build humanistic culture, and develop circular economy and construct green zones.

\section{Acknowledgement}

This research was financially supported by East China University of Political Science and Law under Grant 2017 Science Research Project, Shanghai Social Sciences Planning Project under Grant 2015JG009-BGL307 and the National Social Science Foundation of China under Grant 17BGL099.

\section{References}

[1] REN Hao, ZHEN Jie. 2016 Blue Book on Sustainable Development of Industrial Parks in China, Tongji University Press, 2016:1.

[2] ZHENG Jiang-huai, GAO Chun-liang. Transfer of International Manufacturing Optimal Industrial Linkage and Policy. China Industrial Economy,2005.2:29-36.

[3] WU Jin-ming, ZHANG Pan, ZHAO Zeng-qi. Production Industry Chain, Production Matching Radius and Self-development Capability of an Enterprise. China Industrial Economy, 2005.2:44-50.

[4] LU Lu. On Construction of Smart Park Evaluation System Based on CMM and COBIT Frame. Journal of Southwest China Normal University (Natural Science Edition), 2017.3:128-135. 